This is an open access article under the CC BY-NC-ND license (https://creativecommons.org/licenses/by-nc-nd/3.0/) Issue III, November 2020

ISSN 2707-9481

ISBN 978-601-323-207-2

https://doi.org/10.31643/2020.023

\author{
Aitkenova Gulzhanat Toleutayevna \\ RSE at REM «Republican Research Institute \\ for Labor Protection of the Ministry of Labor \\ and Social Protection of the Population of \\ the Republic of Kazakhstan» Republic of Kazakhstan \\ E-mail:nauka@rniiot.kz \\ ORSID ID:0000-0001-5543-0997
}

\title{
Assessment of compliance of the occupational health management system of a soft drink production company
}

\begin{abstract}
This article presents the results of conformity assessment of the implemented labor protection management system on the example of an enterprise engaged in the production of soft drinks. According to the results of the analysis, in General, the effectiveness of the implementation and functioning of the labor protection management system at the enterprise is estimated as «high». The results obtained on the basis of the Methodology for evaluating the effectiveness of the labor protection management system indicate that the implemented labor protection management system is applicable at domestic enterprises, and the effectiveness assessment in the form of an audit, in turn, will allow timely identification of shortcomings or violations in the labor protection management system at enterprises. The article is based on the results of research on the topic: "Development of scientific and methodological bases for ensuring safe work in priority sectors of the economy of the Republic of Kazakhstan».

Keywords: occupational safety and health, management system, occupational risk management, conformity assessment, criterion, indicator.

Cite this article as: Aitkenova G. T. (2020). Otsenka sootvetstviya sistemy upravleniya okhranoy truda predpriyatiya proizvodstva bezalkogol'nykh napitkov [Assessment of compliance of the occupational health management system of a soft drink production company]. Challenges of Science. Issue III, p.: 159-162. (In Russian). https://doi.org/10.31643/2020.023
\end{abstract}

Айткенова Гульжанат Толеутаевна

РГП на ПХВ «Республиканский

научно-исследовательский институт по охране

труда Министерства труда и социальной

защиты населения Республики Казахстан»

Республика Казахстан, E-mail: nauka@ rniiot.kz

ORSID ID:0000-0001-5543-0997

\section{Оценка соответствия системы управления охраной труда предприятия производства безалкогольных напитков}

Абстракт. В настоящей статье представлены результаты оценки соответствия внедренной системы управления охраной труда на примере предприятия, занимающегося производством безалкогольных напитков. 
По результатам анализа, в целом, эффективность внедрения и функционирования системы управления охраной труда на предприятии оценена как «высокая». Полученные результаты на основе Методики оценки эффективности функционирования системы управления охраной труда, свидетельствуют о том, что внедренная система управления охраной труда применима на отечественных предприятиях, а оценка эффективности в виде аудита, в свою очередь, позволит своевременно выявить недостатки или нарушения в системе управления охраной труда на предприятиях. Статья подготовлена по результатам научно-исследовательских работ по теме: «Разработка научно-методических основ обеспечения безопасного труда в приоритетных секторах экономики Республики Казахстан» (ИРН 61897/ПЦФ-МТСЗН РК-ОТ-20).

Ключевые слова: безопасность и охрана труда, система управления, управление профессиональными рисками, оценка соответствия, критерий, показатель.

Согласно трудовому законодательству Республики Казахстан, внедрение системы управления охраной труда (далее - СУОТ) и осуществление контроля за ее функционированием является обязанностью работодателя [4].

СУОТ на основе управления профессиональными рисками является составной частью системы управления производством, определяет единый порядок подготовки, принятия и реализации решений по осуществлению организационных, технических и санитарно-профилактических мероприятий, направленных на обеспечение безопасных и здоровых условий труда.

В целях дальнейшего снижения уровня производственного травматизма и улучшения условий труда работников, занятых во вредных условиях труда в соответствии с международными нормами, РГП на ПХВ «Республиканский научно-исследовательский институт по охране труда Министерства труда и социальной защиты населения Республики Казахстан» (далее - Институт) в рамках научнотехнической программы проведена научно-исследовательскую работу по разработке научнометодических основ обеспечения безопасного труда в приоритетных секторах экономики Республики Казахстан.

При проведении научно-исследовательской работы, была апробирована СУОТ на 20-ти пилотных предприятиях различных видов экономической деятельности и размерности, разработанная Институтом $[1,2,3]$. В целях оценки эффективности ее функционирования, была разработана соответствующая методика, на которую было получено свидетельство о регистрации авторского права на научное проведение [4].

Методика основана на подходе, согласно которому, определение состояния СУОТ на предприятии осущесвтвляется, используя мониторинг системы, в процессе которого собирается, регистрируется и анализируется определенное количество ключевых признаков (показателей), сгруппированных в критерии, и раскрывающих их суть, учитывая те факторы, которые оказывают влияние на формирование оценочных критериев и показателей. С учетом особенностей разработанной СУОТ, был разработан комплект критериев. Данный комплект состоит из пяти критериев, охватывающих все аспекты внедряемой СУОТ: своевременность выполнения процедур элементов СУОТ; качество выполнения процедур элементов СУОТ; контроль выполнения процедур элементов СУОТ; эффективность управления профессиональными рисками; экономическая эффективность.

Для каждого критерия разработан ряд показателей. Показатели, формирующие каждый критерий, определяются на основе количественного значения, вычисляемого различными способами (с применением формул, уравнений, присваивания баллов). Оценка эффективности системы управления охраной труда позволит оценить результативность внедренной ИСУОТ, включая анализ деятельности системы управления охраной труда на предприятии.

В настоящей статье представлены результаты оценки эффективности и соответствия основным нормативным требованиям СУОТ, внедренной на предприятии, основным видом деятельности которого является производство безалкогольных напитков (далее - Пилотное предприятие).

В 2019 году в ходе выполнения исследований, на основе соглашения о сотрудничестве, была осуществлена оценка профессиональных рисков и, с учетом ее результатов, разработана СУОТ, в элементы которой, входит контроль функционирования и мониторинг реализации процедур, которые принято оценивать в виде аудита. 
Пилотное предприятие относится к субъектам среднего предпринимательства. Общая численность работников по штатному расписанию не превышает 200 человек. Профессиональноквалификационная структура предприятия состоит из 31 профессий. От общей численности работников, 69\% занимают работники основного производственного персонала, $20 \%$ административный персонал и $11 \%$ вспомогательный производственный персонал.

В процессе изучения СУОТ на Пилотном предприятии были выявлены несоответствия требованиям законодательства в процедурах обучения и инструктажа работников, обеспечения СИЗ и контроля за соблюдением требовании по БиОТ.

Результаты оценки по каждому критерию, согласно Методике, распределены в соответствии с показателями эффективности. Степень эффективности ранжирована в зависимости от процентного значения, следующим образом: высокая (100-85 \%), выше среднего (84-80\%), средняя (79-75\%), ниже среднего (74-60 \%) и низкая (59\% и менее).

По результатам анализа, в целом, эффективность внедрения и функционирования СУОТ на предприятии оценена как «высокая» $(99,6 \%)$.

На исследуемом предприятии для всех категорий работников своевременно и качественно проводятся процедуры обучения и все виды инструктажа, предварительного и периодического медицинского осмотров, обеспечение сертифицированными средствами индивидуальной защиты.

Также, все рабочие места охвачены аттестацией рабочих мест по условиям труда и проведена оценка профессиональных рисков. Соблюдены своевременность и полнота выполнения мероприятий по безопасности и охране труда. На предприятии не зарегистрировано ни одного несчастного случая на производстве, а также инцидентов угрожающих жизни и здоровью работников в период внедрения СУОТ.

Таким образом, построение эффективной системы управления охраной труда на предприятии способствует снижению затрат и положительным образом отражается не только на сохранении жизни и здоровья работников, но и влияет на их мотивацию к безопасному труду, и способствует повышению производительности и прибыльности предприятия.

Оценка соответствия и эффективности функционирования СУОТ предусмотрена в качестве регулярного применения работодателем самостоятельно или с привлечением экспертов. Методика довольно проста и не требует значительных затрат времени и усилий со стороны эксперта/специалиста, проводящего анализ.

Отмечена высокая заинтересованность и соответствующая квалификация руководства предприятия. Полученные результаты дают основания считать СУОТ, разработанную в ходе научноисследовательских работ, эффективной, простой в применении, действенной. Это подтверждается в целом положительными результатами апробации СУОТ на 20-ти пилотных предприятиях, средняя эффективность внедрения СУОТ, на которых показала 93\%, что соответствует оценке «высокая».

Ссылка на данную статью: Айткенова Г.Т. (2020) Оценка соответствия системы управления охраной труда предприятия производства безалкогольных напитков. Материалы Международной практической интернет-конференции «Актуальные проблемы науки» [Challenges of Science]. Выпуск III, стр. 159-162. https://doi.org/10.31643/2020.023

\section{Литературы}

[1] Трудовой кодекс Республики Казахстан ЗРК № 414-V от 23 ноября 2015г. URL:http://adilet.zan.kz/rus/docs/K1500000414

[2] Бисакаев С.Г., Абикенова Ш.К., Есбенбетова Ж.Х. Методические рекомендации по внедрению системы управления профессиональными рискам на предприятии / Бисакаев С.Г., Абикенова Ш.К., Есбенбетова Ж.Х. Астана: РГКП «РНИИОТ МТЗСН РК», Астана, 2017 г. - С. 58.

[3] Ж. Х. Есбенбетова, Р.Т. Шайхы, А. Е. Танабаева, Г.Т. Айткенова. Инновационные подходы к разработке новой системы управления охраной труда. //журнал «Вестник ВКГТУ», ВКГТУ им. Д. Серикбаева, г. Усть Каменогорск, № 3, 2019г. С 168-170.

[4] Айткенова Г. (2019), Разработка интегрированной системы управления охраной труда на преприятии транспротной отрасли. Материалы Международной практической интернет-конференции «Актуальные проблемы науки» / 


\section{Materials of International Practical Internet Conference "Challenges of Science”}

Materials of International Practical Internet Conference "Challenges of Science”. ISBN 978- 601-323-144-0. Выпуск II, 2019. Стр.: 110-114. https://doi.org/10.31643/2019.022

[5] Методика оценки эффективности функционирования интегрированной системы управления охраной труда на основе управления профессиональными рисками (научное произведение) / Авторы: Бисакаев С.Г., Джумагулова Н.Г., Есбенбетова Ж.Х., Танабаева А.Е., Айткенова Г.Т. / Свидетельство №9304 от 17.04.2020 г.

\section{References}

[1] Trudovoy kodeks Respubliki Kazakhstan ZRK № 414-V ot 23 noyabrya [Labor Code of the Republic of Kazakhstan 3PK No. 414-V dated November 23], 2015. URL:http://adilet.zan.kz/rus/docs/K1500000414 (In Russian).

[2] Bisakayev S.G., Abikenova SH.K., Yesbenbetova ZH.KH. Metodicheskiye rekomendatsii po vnedreniyu sistemy upravleniya professional'nymi riskam na predpriyatii [Methodical recommendations for the implementation of a professional risk management system at an enterprise] / Bisakayev S.G., Abikenova SH.K., Yesbenbetova ZH.KH. Astana: RGKP «RNIIOT MTZSN RK», Astana, 2017 g. - S. 58. (In Russian).

[3] Zh. Kh. Yesbenbetova, R.T. Shaykhy, A. Ye. Tanabayeva, G.T. Aytkenova. Innovatsionnyye podkhody k razrabotke novoy sistemy upravleniya okhranoy truda [Innovative approaches to the development of a new OSH management system]. //zhurnal «Vestnik VKGTU», VKGTU im. D. Serikbayeva, g. Ust' - Kamenogorsk, № 3, 2019g. S 168-170. (In Russian).

[4] Aytkenova G. (2019), Razrabotka integrirovannoy sistemy upravleniya okhranoy truda na prepriyatii transprotnoy otrasli [Development of an integrated OSH management system at a transport industry enterprise]. Materialy Mezhdunarodnoy prakticheskoy internet-konferentsii «Aktual'nyye problemy nauki» / Materials of International Practical Internet Conference "Challenges of Science". ISBN 978- 601-323-144-0. Vypusk II, 2019. Str.: 110-114. https://doi.org/10.31643/2019.022 (In Russian).

[5] Metodika otsenki effektivnosti funktsionirovaniya integrirovannoy sistemy upravleniya okhranoy truda na osnove upravleniya professional'nymi riskami (nauchnoye proizvedeniye) [Methods for assessing the effectiveness of the functioning of an integrated OSH management system based on occupational risk management (scientific work)] / Avtory: Bisakayev S.G., Dzhumagulova N.G., Yesbenbetova ZH.KH., Tanabayeva A.Ye., Aytkenova G.T. / Svidetel'stvo №9304 ot 17.04.2020 g. (In Russian). 